\title{
Detecting selective digestion of meiobenthic prey by juvenile spot Leiostomus xanthurus (Pisces) using immunoassays*
}

\author{
Debra S. Scholz ${ }^{1}$, Lara L. Matthews ${ }^{2}$, Robert J. Feller ${ }^{3}$ \\ ${ }^{1}$ Belle W. Baruch Institute for Marine Biology and Coastal Research, University of South Carolina, Columbia, South Carolina \\ 29208, USA \\ ${ }^{2}$ Curriculum in Marine Science, University of North Carolina - Chapel Hill, Morehead City, North Carolina 28557, USA \\ ${ }^{3}$ Department of Biological Sciences, Marine Science Program, and Belle W. Baruch Institute for Marine Biology and Coastal \\ Research, University of South Carolina, Columbia, South Carolina 29208, USA
}

\begin{abstract}
Several past studies have shown that juvenile spot Leiostomus xanthurus feed selectively upon meiobenthic harpacticoid copepods. However, nematodes outnumber harpacticoids by nearly $4: 1$ in muddy sediments where juvenile spot feed by taking mouthfuls of the substrate. Therefore, we tested whether selective or rapid digestion of nematodes might account for the reported dominance of harpacticoid copepods in juvenile spot dietary studies. In separate feeding trials, starved spot (20 to 48 $\mathrm{mm} \mathrm{SL)}$ were fed either nematodes or epibenthic copepods and then were serially sacrificed over a 5 to $8 \mathrm{~h}$ period. Antisera specific to each prey taxon were used to quantify the amounts of soluble prey antigens remaining in both foregut and hindgut of each fish. Using rocket immunoelectrophoresis (RIE), we detected nematode antigens for at least $5 \mathrm{~h}$ after ingestion, while antigens from copepods were detected for only $1.25 \mathrm{~h}$. Visual inspection of gut contents, however, showed nearly opposite results. Nematodes were unrecognizable about $2 \mathrm{~h}$ after ingestion, while exoskeletons of copepods remained identifiable throughout their $8 \mathrm{~h}$ residence in the fish's gut. Because nematodes are digested rapidly, dietary profiles for juvenile spot may be biased towards hardbodied prey such as the exoskeletons of harpacticoid copepods. Thus the elapsed time between prey ingestion and spot collection can greatly influence dietary analyses. The importance of nematode prey for juvenile spot has probably been greatly underestimated.
\end{abstract}

\section{INTRODUCTION}

Spot Leiostomus xanthurus Lacepede inhabits the eastern seaboard and estuaries of the USA and the Gulf of Mexico (Roelofs 1954, Chao \& Musick 1977). Larval spot feed on plankton until, at a standard length (SL) of 20 to $30 \mathrm{~mm}$, the mouth becomes sub-terminal and feeding is conducted by taking mouthfuls of surficial sediment. The sediment is then strained through the gill lamellae's bucco-pharyngeal sieve for retention of food items and expulsion of unwanted particles through the opercular opening (Yetman 1979). Juvenile spot preferentially feed on muddy rather than sandy estuarine sediments (Smith \& Coull 1987).

\footnotetext{
- Contribution no. 838, Belle W. Baruch Institute for Marine Biology and Coastal Research
}

Numerous authors report that juvenile and young-ofthe-year spot feed opportunistically on meiobenthic prey (especially harpacticoid copepods) inhabiting these sediments (Coull 1990).

When prey items are consumed which contain digestion-resistant hard parts, e.g. copepod exoskeletons and polychaete setae, a potential for bias in dietary profiles may result if visual gut contents analysis is performed. These hard parts can remain distinguishable after long periods of residence in the gut. Copepod exoskeletons were retained for periods exceeding $8 \mathrm{~h}$ in a dragonet fish's digestive tract (Sogard 1984). However, soft-bodied prey are quickly digested beyond visual recognition. Hofsten et al. (1983) showed that nematodes underwent significant digestion after only $0.5 \mathrm{~h}$ and were no longer visible after a $2.5 \mathrm{~h}$ digestive period in the fish Danio sp. Visual bias may be further 
enhanced in dietary profiles with the presence of 'undefined remains' or indistinguishable, amorphous material. Mastication or differential digestion of commonly or inadvertently consumed prey may have occurred in these instances.

Juvenile spot exhibit a diel feeding periodicity. Their guts are fullest following high tide and emptiest shortly after low tide, such that gut contents evacuation time is ca $6 \mathrm{~h}$ in the field (Archambault \& Feller 1991). Since many of the study results cited by Coull (1990) were based on spot samples collected at low tide, significant digestion of their gut contents may have already taken place. Differential rates of digestion among prey items thus becomes an important factor to consider when determining dietary profiles (Hyslop 1980). With visual inspection of gut contents as the sole method for dietary analysis, bias in describing feeding habits, dietary profiles, feeding periodicities, digestion rates, feeding selectivity or daily rations is thus highly likely. Additionally, gear selection may introduce bias if a nonrepresentative sample of the fish population is collected for analysis (Hayward et al. 1989).

Nematodes are usually the most numerous taxon in muddy sediments. In North Inlet, South Carolina, USA, they numerically comprise nearly $70 \%$ of the total meiofaunal community with copepods ranking second at $17 \%$ (Coull 1985). In the present study, spot were collected in areas where nematodes comprised up to $96 \%$ of the total number of meiofauna in surficial sediments (Billheimer \& Coull 1988). If spot fed opportunistically or non-selectively, numerical counts and proportions of prey in their gut contents should closely mirror those found in the feeding substrate. When visual inspection and enumeration are the only basis for compiling dietary profiles, the disproportionate predominance of copepods in juvenile spot gut contents suggests that these fish selectively prey upon harpacticoid copepods. Additional support for the view that juvenile spot feed selectively upon harpacticoids, especially epibenthic forms, comes from experimental studies by Nelson \& Coull (1989) and Ellis \& Coull (1989). Both these studies demonstrated that surfacedwelling species were more susceptible to predation than burrowing or interstitial forms and that the motile behavior of harpacticoids may prompt their selection over other types of prey similar in size.

This study was designed to test the hypothesis that selective or rapid digestion of nematode prey could account for the apparent dominance of harpacticoid copepod prey in juvenile spot diets. Utilizing a sacrificial series of timed digestive periods, spot gut contents were analyzed visually and serologically to determine the rate of nematode and copepod prey disappearance from both foregut and hindgut portions of the digestive tract. By comparing the 2 methods of diet analysis, the bias resulting from selective digestion when visual inspection alone is used could be determined.

\section{METHODS AND MATERIALS}

Antigen and antibody preparation. Nematodes were extracted from their natural sediment on several occasions from January to September 1987 following methods of Couch (1988). After extraction, the nematodes were placed in filtered seawater and incubated in a dark refrigerator at $4^{\circ} \mathrm{C}$ for $24 \mathrm{~h}$ to allow the evacuation of any previously eaten meals. Periodic water changes were made to remove fecal wastes. Following incubation, excess seawater was removed and the nematodes were then frozen at $-20^{\circ} \mathrm{C}$. Species identifications were not performed. After $1 \mathrm{mg}$ live mass (ca 500000 individuals) had been collected, the nematodes were thawed, centrifuged to a pellet, and the supernatant discarded. Additional nematode pellets were consolidated and homogenized with $2 \mathrm{ml}$ of a saline buffer solution (TES, N-tris[hydroxymethyl] methyl-2-aminoethane sulfonic acid, $\mathrm{pH}$ 7.3) to form the nematode antigen having a final soluble protein concentration of $1.45 \mathrm{mg} \mathrm{ml}^{-1}$. The immunization protocol for producing antibodies in New Zealand white female rabbits was carried out by Cocalico Biologicals, Inc. following Feller et al. (1979). The resulting rabbit serum contained polyclonal antibodies for detecting soluble nematode antigens in spot gut contents. The nematode antiserum had a titer of 128 using double immunodiffusion tests wherein the full strength homologous antigen was diluted successively by halves until no precipitin reaction was observed.

Copepods were extracted from the uppermost $2 \mathrm{~cm}$ of surficial mud in the same tidal creeks where nematodes were collected by first sieving the mud through a $0.250 \mathrm{~mm}$ mesh and then placing material remaining on the sieve into a shallow plastic tray containing natural seawater. The tray was illuminated with a high intensity cool light source and the positively phototactic copepods were collected with a siphon. The copepod polyclonal antiserum (titer $=64$ ) utilized to analyze spot stomach contents for solubilized copepod protein was prepared similarly to the nematode antiserum from a stock antigen of starved copepods (100 $\mathrm{mg}$ wet wt in $5 \mathrm{ml}$ TES) having a final protein concentration of $0.2 \mathrm{mg} \mathrm{ml}^{-1}$.

Both antisera were tested for cross-reactions using double immunodiffusion against antigenic extracts of spot muscle tissue, stomach fluids from starved spot, and against antigenic extracts of both copepods and nematodes. Each antiserum was also calibrated for

- Route 272, PO Box 265, Reamstown, PA 17567, USA 
sensitivity to determine how few individuals could be detected, assuming that all nematodes contained the same amount of soluble protein per individual and likewise for all copepods. One thousand nematodes were picked at random from an extracted sediment sample and solubilized in $0.1 \mathrm{ml}$ TES buffer. The nematode antiserum produced a weak but distinct precipitin line with as little as a $0.5 \%$ aliquot of the macerate (an amount representing ca 5 unit nematodes of average size) when tested with rocket immunoelectrophoresis ([RIE] - see 'Gut contents analysis' below). The copepod antiserum was tested against a dilution series of a slurry of 1000 copepods ground up in $0.1 \mathrm{ml}$ TES buffer. Again using RIE, the lower limit of detection for copepods was between 75 and 125 unit individuals.

Fish feeding experiments. The basic experimental set-up was feeding starved juvenile spot a meal of either nematodes alone or harpacticoid copepods alone. Fish were then isolated from the food and serially sacrificed for both visual analysis and quantitative immunoassay of their gut contents. At the end of each trial's respective digestion period, all fish were removed and quick frozen to halt further digestion of the meal. Three starved fish served as non-feeding controls in each single-prey experiment.

Several hundred juvenile spot (20 to $48 \mathrm{~mm} \mathrm{SL}$ ) were collected during May and June 1987 in tidal creeks around Oyster Landing in North Inlet $\left(33^{\circ} 20^{\prime} \mathrm{N}\right.$,

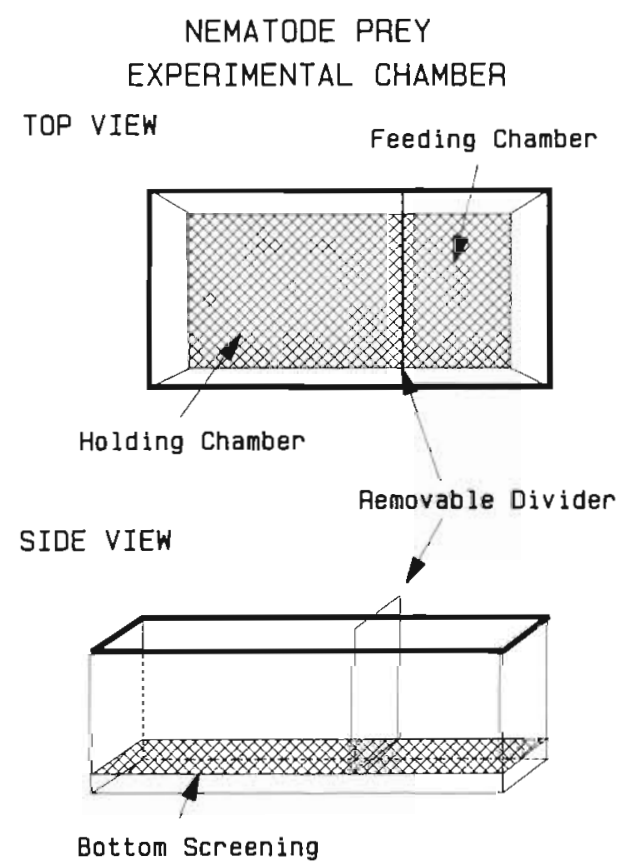

Fig. 1. Schematic of experimental chamber illustrating the feeding and holding or digestion areas with mesh used to keep fish from feeding on the bottom. The petri dishes containing nematodes were placed into the feeding area $79^{\circ} 10^{\prime} \mathrm{W}$ ). Fish were seined (10 mm mesh) at low tide and transferred to a flow-through, filtered seawater holding table where they were subsequently starved for 24 to $36 \mathrm{~h}$ for evacuation of any previously eaten meals which might interfere with the immunoassays. Fecal wastes were periodically siphoned from the holding table. Only healthy fish were used in feeding experiments. Two separate feeding experiments were conducted during summer 1987 - one utilizing nematodes as prey, the other using benthic copepods. Mixed prey feeding experiments were not performed.

Nematode prey. The feeding chambers consisted of four 20 gallon $(79.21$ ) rectangular aquaria each measuring $76 \times 30 \times 30 \mathrm{~cm}$ (Fig. 1). Each aquarium was sectioned into 2 isolated chambers by a removable divider. To prevent spot from consuming any errant food or fecal debris during the non-feeding phase of the experiment, plastic windowscreen mesh $(1 \mathrm{~mm})$ was affixed $2.5 \mathrm{~cm}$ above the floor of the aquarium. Constant seawater inflow $\left(26^{\circ} \mathrm{C}, 30 \mathrm{ppt}\right.$ salinity) was maintained using a flow-through system entering and exiting the top of the aquaria. Inflowing seawater was initially passed through a $1 \mu \mathrm{m}$ mesh filter bag to remove any organisms present in the water column which could serve as possible food sources. To minimize possible distractions from outside observers, the upright exterior walls and floors of the aquaria were covered with black, opaque plastic. The top of each aquarium remained open to ambient light levels existing inside the seawater laboratory.

Azoic mud was prepared by heating surficial intertidal mud at $200^{\circ} \mathrm{C}$ for $12 \mathrm{~h}$, then homogenizing it with freshwater, and finally letting it soak in filtered running seawater for $12 \mathrm{~h}$ to stabilize its salinity and to flush out organics. To simulate an actual feeding substrate, azoic mud was placed in $100 \times 15 \mathrm{~mm}$ round plastic petri dishes until the sediment was flush with the lip. Nematodes were collected in the same tidal creek where fish were collected and extracted live following Couch (1988) so that fresh, live prey were available for the feeding experiment. Thousands of the live nematodes were pipetted onto the azoic mud's surface and were allowed to acclimate for $2 \mathrm{~h}$. Microscopic examination of subsamples of the mud + nematode mixture indicated that the nematodes had burrowed into the mud and were active. The petri dishes were covered with lids and placed gently by hand, 2 per aquarium, into the feeding end of the tanks. The lids were carefully removed, and any floc was allowed to settle inside the feeding chamber.

Sixteen starved spot were allowed to acclimate in the holding portion of the aquaria for $1 \mathrm{~h}$. The divider was removed and a $30 \mathrm{~min}$ feeding period commenced with the first foraging effort displayed in each tank. Feeding was observed in all tanks until it became too cloudy to 
see. At the end of $30 \mathrm{~min}$, the spot were encouraged to depart the feeding chamber and the divider was replaced. Despite efforts to prevent nematode prey from getting into the holding area, some muddy water entered when the fish were herded. The material soon settled to the bottom beneath the mesh, and no fish were observed feeding in the holding area.

For the nematode prey feeding trials, digestion periods increased in each successive feeding trial by $0.5 \mathrm{~h}$ increments. The feeding trials were repeated in series until an uninterrupted digestion period of $5 \mathrm{~h}$ had been attained. In all, 11 digestion time periods were allotted $(0,0.5,1.0,1.5,2.0,2.5,3.0,3.5,4.0,4.5$, and $5.0 \mathrm{~h}$ ) using a total of 336 spot, 176 spot in the 25 May feeding trials and 160 on 11 June 1987, when there was no $4.5 \mathrm{~h}$ trial.

Benthic copepod prey. Feeding aquaria were similar to those used for the nematode feeding trials except that they were smaller $(20 \times 15 \times 20 \mathrm{~cm})$ and did not have separate feeding and digestion chambers. Azoic sediment cleaned as above was placed into each feeding aquarium and allowed to settle before 3 starved spot were added and allowed to acclimate for $30 \mathrm{~min}$. Live copepods were extracted from surficial mud using methods described above. Hundreds of live epibenthic and shallow burrowing harpacticoid copepods (both copepodites and adults, primarily Enhydrosoma propinquum, Microarthridion littorale, Nannopus palustris, Stenhelia bifidia, Pseudobradya pulchella and the cyclopoid Halicyclops coulli) were than added to the feeding aquarium with a pipette and the fish were allowed to feed for $30 \mathrm{~min}$. At the end of the feeding period, fish were transferred (with a water-filled cup so that they never touched a mesh) to a digestion aquarium and serially sacrificed after specified intervals. Each digestion aquarium had windowscreen mesh above the bottom to prevent feeding on fecal material. Three fish were sacrificed every $15 \mathrm{~min}$ for the first $2 \mathrm{~h}$ and then at $1 \mathrm{~h}$ intervals until a single $8 \mathrm{~h}$ time series was achieved.

Gut contents analysis. The entire digestive tract was removed from each fish. The gut was divided into foregut and hindgut with the division immediately posterior to the pyloric caecum. The contents of each portion were removed and inspected for the presence of meiofaunal prey using a dissecting microscope. The number of identifiable prey within each gut section was recorded and contents were then collected in 1.5 $\mathrm{ml}$ vials and frozen for immunoassay analysis. Additionally, fecal remains from the copepod digestion experiment were collected and frozen for further analyses to determine whether prey proteins were in fact degraded.

Rocket Immunoelectrophoresis (RIE): For quantifying the concentration of solubilized prey protein pres- ent in a spot's digestive tract, Laurell's (1966) RIE technique was applied. This immunoassay allows one to measure the amount of soluble protein contained in a known volume of gut contents sample. By calibrating the assay with a known concentration of bovine serum albumin (BSA) as an internal standard, the amount of prey material was measured as the area beneath a rocket-shaped precipitin line following Hentschel \& Feller (1990). The assays were conducted on $25 \times 75$ $\mathrm{mm}$ microscope slides coated with an agarose gel containing antiserum to the target prey organism. Each slide had small wells into which samples (ca $15 \mu$ l) from an individual fish's foregut and hindgut are introduced along with a $2 \mu \mathrm{l}$ spike of BSA antigen (Fig. 2). The agarose gel was comprised of a mixture of agarose and $16 \%$ nematode (or $20 \%$ for copepod) antiserum plus $2 \%$ anti-BSA (by volume). The area under the resulting rocket-shaped immunoprecipitin peak was calculated and is directly proportional to the amount of protein present in the antigen well. For analysis of nematode prey gut contents samples, electrophoresis was conducted at room temperature for $7 \mathrm{~h}$ at constant potential of $2 \mathrm{~V} \mathrm{~cm}^{-1}$ measured and averaged across all slides in a run. Individual samples from the copepod feeding experiment were run in duplicate for $6 \mathrm{~h}$ at $2 \mathrm{~V}$ $\mathrm{cm}^{-1}$ at room temperature.

RIE was run in duplicate for each of the 16 individual fish at each digestion time for both replicates of the nematode feeding experiment, yielding a total of 672 slides for 176 undiluted spot gut content samples. Gut content samples from the copepod feeding experiment were diluted with and ground in $45 \mu \mathrm{l}$ TES buffer and centrifuged for $5 \mathrm{~min}$ at $600 \times \mathrm{g}$ prior to immunoassay.

Positive identification of meals: To confirm that precipitin peaks obtained with the quantitative RIE assays

\section{TIME SERIES ROCKET IMMUNOELECTROPHORESIS}

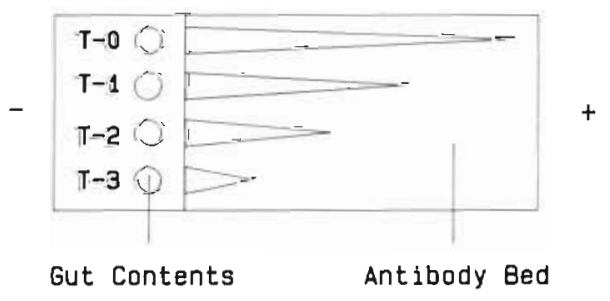

Fig. 2. Rocket immunoelectrophoresis (RIE). A $25 \times 75 \mathrm{~mm}$ microscope slide is coated with agarose and an antibody bed matrix. Antigen wells $(3.0 \mathrm{~mm}$ dia.) are punched in the agarose portion of the slide and $15 \mu \mathrm{l}$ of test antigen is placed in the wells. The antigens are electrophoresed from negative to positive through the antibody bed. Precipitin lines emerge as the antigen forms a complex with its homologous antibody. As concentrations of this complex equilibrate, a rocket-shaped peak results. The area under the rocket peak corresponds to the antigen concentration in the well 
were actually formed with target prey antigens, both double immunodiffusion and tandem 2-dimensional electrophoretic (tandem 2-D) techniques (Krøll 1983) were used. Gut contents from the 3 earliest digestive time periods were analyzed using tandem 2-D's for both foregut and hindgut portions. These immunoassays all clearly demonstrated that the soluble antigenic material detected in gut contents by the nematode and copepod antisera were identical to those used to prepare the respective antisera. Fused-RIE, a technique similar to tandem 2-D, has also been used to confirm prey identities in gut contents immunoassays by Grisley \& Boyle (1988) and Pierce et al. (1990).

Data analysis. Nematode feeding experiment: The 2 foregut and hindgut peak area measurements $(x)$ for each replicate RIE were transformed $\left(\log _{10}(x+1)\right)$ to achieve homoscedasticity. Linear regression was conducted on the log-transformed peak area data to determine if any significant time trend in nematode protem degradation had occurred. Due to high variance in the entire transformed data set, the analysis was conducted on results from only the top 2 nematode consumers (determined from largest peak areas) for each time period in both experimental replicates. Many of the fish did not feed at all (a bully effect). Those that did feed

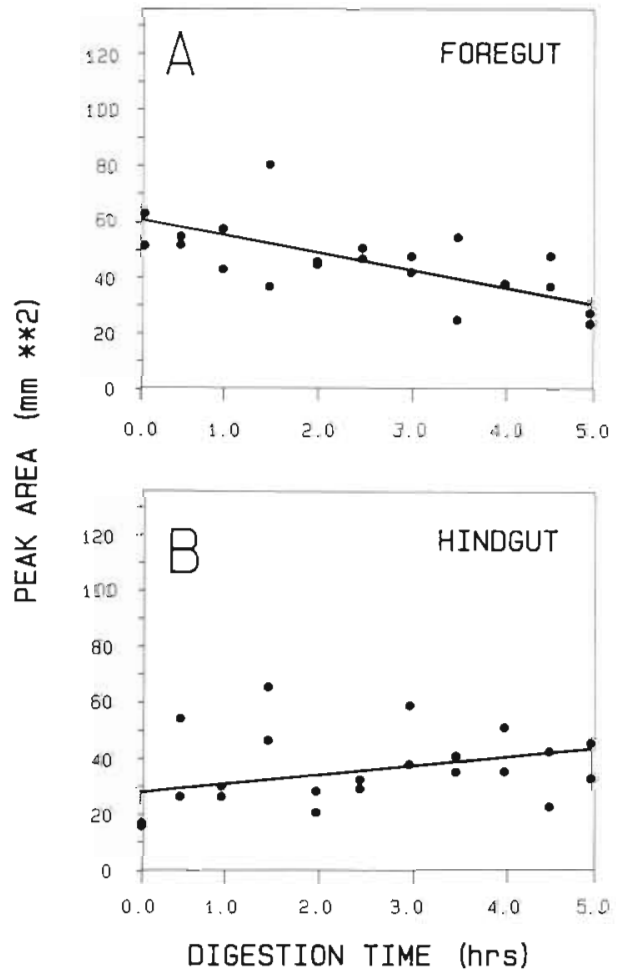

Fig. 3. Leiostomus xanthurus. Mean peak areas measured from RIE electrophorograms for the top 2 spot feeding on nematodes. (A) Foregut contents. Equation of line is: $Y=$ $-0.056-4.66 T_{1} r^{2}=0.52$, where $Y=$ peak area $(\mathrm{mm})$ and $T=$ time (h). (B) Hindgut contents. Equation of line is: $Y=0.033+$ $1.78 T, \mathrm{I}^{2}=0.44$ ate only very small quantities of nematodes. The fullest gut content found was much smaller than the size of meals consumed by spot in the wild (Archambault \& Feller 1991). Therefore, the 2 greatest prey protein concentrations obtained from all 16 fish within each replicate time period were assumed to be most representative of naturally feeding fish.

Copepod feeding experiment: Due to the small meal sizes ingested and the lower sensitivity of the copepod antiserum, it was necessary to combine the gut contents of all 3 fish from each digestion time period. This yielded only one foregut and one hindgut sample (of larger volume) from each digestion interval for duplicate immunoassays. To ensure complete solubilization of antigenic proteins, all samples after $2 \mathrm{~h}$ digestion time were freeze-dried and later reconstituted to their original volume in TES buffer prior to analysis by RIE.

\section{RESULTS}

\section{Antibody specificity and sensitivity}

Using double immunodiffusion tests, the nematode antibody reacted only with its homologous nematode antigen. The copepod antiserum also tested positive only with its homologous antigen and negative with heterologous antigens. That is, the nematode antiserum would detect only soluble nematode proteins and the copepod antiserum detected only soluble copepod proteins.

Antigens detected using RIE with foregut and hindgut samples were confirmed as having come from ingested nematode prey using tandem 2-D assays. The resultant peaks showed immunological identity, as both foregut and hindgut samples coalesced with the nematode antigen. To determine if sample peaks found with RIE in late $(4.0$ to $5.0 \mathrm{~h})$ foregut and early $(0.0$ to $1.0 \mathrm{~h}$ ) hindgut digestion times were actually nematode antigens, tandem 2-D analysis showed that the sample gut contents in question were identical to the homologous nematode antigen. Tandem 2-Ds were deemed unnecessary for additional confirmation of the copepod antiserum's specificity.

\section{Feeding experiments}

Using data for the top 2 consumers of nematodes, the regression of log-transformed RIE peak areas with time of digestion in the foregut was highly significant $(p<$ 0.0002 ; Fig. $3 \mathrm{~A}$ ). The trend towards increasing concentrations in the fish's hindguts was not significant ( $p<$ 0.09; Fig. 3B).

With more frequent measurements early in the 


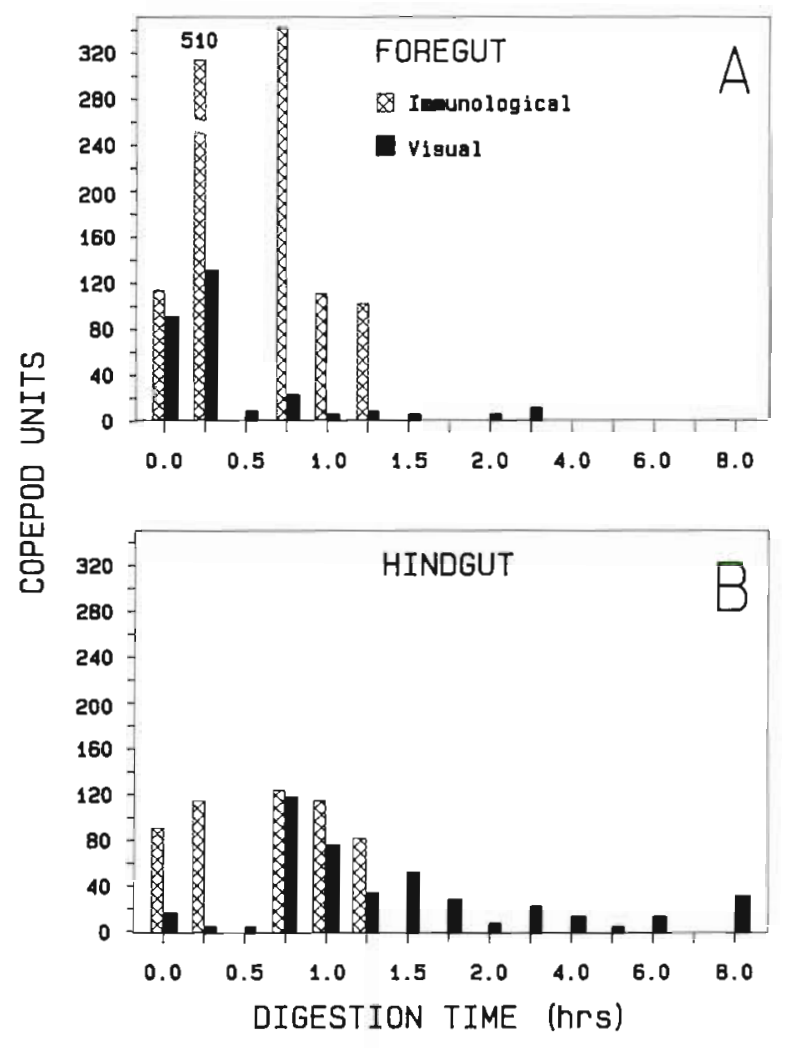

Fig. 4. Leiostomus xanthurus. Concentration of soluble antigens from the consumed copepod meals in juvenile spot. (A) Foregut contents; (B) hindgut contents. Fish at 0.5 h postingestion either did not feed or contained soluble prey protein levels below the limits of detection

copepod feeding experiment, a $0.5 \mathrm{~h}$ lag between foregut and hindgut soluble prey protein concentrations was detected. Concentrations in the foregut increased initially, peaking after about $0.25 \mathrm{~h}$, and subsequently decreased below the level of detection after $1.5 \mathrm{~h}$ (Fig. 4). The trend was similar in the hindgut, also with a 0.5 $\mathrm{h}$ lag. The 3 fish sacrificed $30 \mathrm{~min}$ into the copepod digestion period apparently did not feed or ate too few copepods to be detected (Fig. 4).

\section{Comparing visual analysis and immunoassay by RIE}

Visual quantification of nematode prey in foregut samples lacked accuracy after only 1 h of digestion, as most prey were at least partially degraded by then (Fig. 5). Nematodes were seldom distinguishable in the foregut by visual analysis for digestive time periods exceeding 1.5 to $2 \mathrm{~h}$, although a few were still identifiable up to $3 \mathrm{~h}$ digestion time. However, consumed nematode protein was detectable with the nematode antibody probe for the entire $5.0 \mathrm{~h}$ digestion time period in both foregut and hindgut samples. A portion of the meal apparently
Table 1. Leiostomus xanthurus. Number of spot which had eaten or not eaten nematodes as determined by immunological analysis of foregut and hindgut contents. Time = digestion time for meal. Both experimental replicates were combined for this analysis

\begin{tabular}{|lcccc|}
\hline $\begin{array}{l}\text { Time } \\
\text { (h) }\end{array}$ & \multicolumn{2}{c}{ Foregut } & \multicolumn{2}{c|}{ Hindgut } \\
\hline 0.0 & Eaten & Not eaten & Eaten & Not eaten \\
0.5 & 18 & 14 & 9 & 23 \\
1.0 & 18 & 14 & 8 & 24 \\
1.5 & 16 & 16 & 9 & 23 \\
2.0 & 10 & 22 & 8 & 24 \\
2.5 & 10 & 22 & 6 & 26 \\
3.0 & 12 & 20 & 7 & 25 \\
3.5 & 16 & 16 & 3 & 29 \\
4.0 & 8 & 24 & 8 & 24 \\
4.5 & 10 & 22 & 11 & 21 \\
5.0 & 2 & 14 & 7 & 16 \\
& 4 & 28 & 4 & 28 \\
\hline
\end{tabular}

moved very quickly through the gut in these previously starved fish, as solubilized nematode antigens were detected in the hindguts of fish immediately following the half-hour feeding trial at time zero (Table 1). Immunological assays indicated that the proportion of fish with nematodes in their foreguts decreased with time, but the proportion of fish with nematodes in the hindgut stayed more constant over time (Table 1).

We could visually identify copepods in the foregut for up to $3 \mathrm{~h}$, but immunologically for only $1.25 \mathrm{~h}$ (Fig. 6A). Visual detection of copepod prey peaked after the 0.25 h digestion period, but immunological detection was highest between 0.25 and $0.75 \mathrm{~h}$ (Fig. 6A). Immunological detection stopped almost 2 h earlier than visual detection in the foregut (Fig. 6A). In the hindgut, visual detection was possible throughout the entire $8 \mathrm{~h}$ digestion period, except for the fish at $7 \mathrm{~h}$ (Fig. 68). Peak numbers were found in the hindgut at $0.75 \mathrm{~h}$ post-

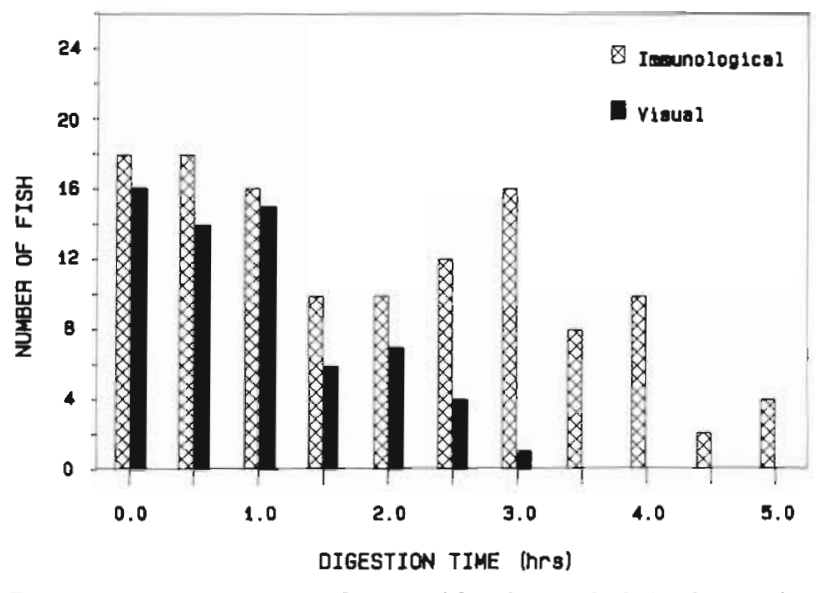

Fig. 5. Leiostomus xanthurus. Number of fish from the nematode feeding trials (both replicates combined) that contained visually or immunologically identifiable nematode remains in their foreguts 


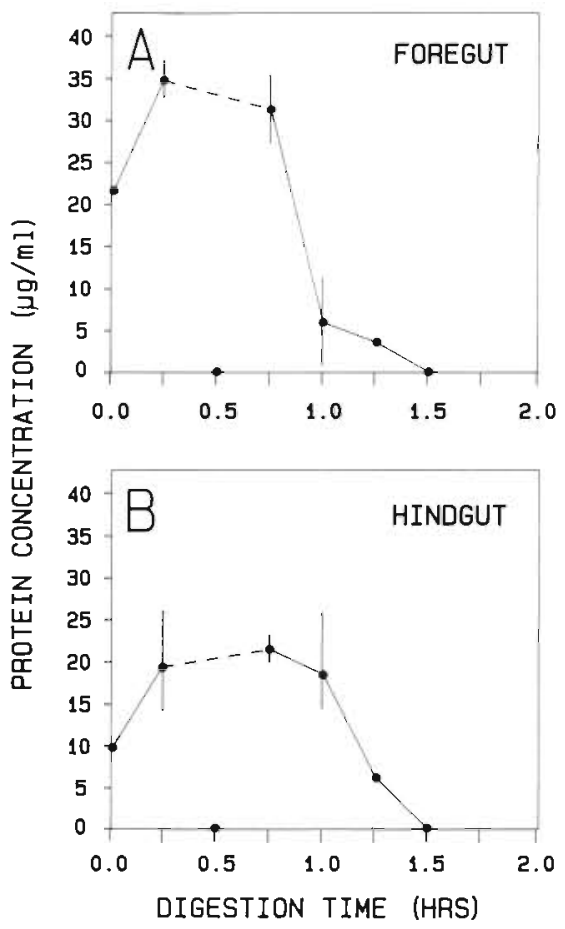

Fig. 6. Leiostomus xanthurus. Mean peak areas from replicate analyses (by RIE) of spot gut contents in the copepod feeding trials. A copepod unit is a visual count of one prey item. including both intact, undigested animals and empty exoskeletons, or the concentration of soluble protein from one standard copepod. (A) foregut contents; (B) hindgut contents. Vertical bars denote $95 \%$ confidence intervals about the mean

ingestion, but it took longer than an additional $0.75 \mathrm{~h}$ for prey to disappear from the hindgut (Fig. 6B).

The abrupt increase in visual detection of copepod exoskeletons in the hindgut corresponded directly with a comparable decrease in copepods visually detectable in the foregut. On the other hand, a gradual increase in immunological detection indicated a steady flow of solubilized copepod prey antigens from the foregut to the hindgut. Immunological detection in both regions of the gut ceased after $1.25 \mathrm{~h}$ of digestion time when the bulk of the copepod exoskeletons had passed through the spot gut. Our inability to detect copepod prey antigens in any spot fecal remains indicated that the meal was completely processed to the point that it became unrecognizable with the antiserum probe used. Thus empty exoskeletons were left to complete passage through the gut prior to defecation.

\section{DISCUSSION}

Although nematodes are the overwhelming numerical dominant among meiofaunal taxa in marine sediments worldwide, a great variety of bottom-feeding fishes consume harpacticoid copepods instead (Gee
1989). Juvenile spot also appeared to be heavily selective in feeding mostly upon epibenthic copepods. The predominance of harpacticoid copepods in gut contents of spot collected at low tide - however, see Archambault \& Feller (1991) - suggested that selective or more rapid digestion of nematodes might account for this apparent selectivity.

The inability of traditional visual gut content analytical methods to reliably detect nematode prey in juvenile spot called for the use of serological methods. The polyclonal antisera developed for the study were adequate for the purposes intended. Tests of identity and sensitivity showed a lack of potentially interfering cross-reactivity and the capability of detecting the small numbers of prey consumed in the feeding experiments. The copepod antiserum was not, however, as sensitive as the nematode antiserum. This probably prevented our being able to detect the soluble portions of copepod meals for longer than $1.25 \mathrm{~h}$. A more sensitive, higher titered, antiserum would allow detection of soluble antigens from meals containing many fewer individual copepods.

A further complication in the study was our inability to control meal sizes. Juvenile spot are a social, schooling species and behavec unpredictably when we tried to feed them in densities low enough to allow an individual's feeding behavior to be observed. Neither passively feeding spot pellets of fresh copepods encased in gelatin nor force feeding them copepods was successful. By allowing juvenile spot to assume their 'normal' feeding behavior in small schools, meal sizes consumed varied greatly among individuals, possibly due to the existence of dominance hierarchies among the fish. With one dominant fish doing most of the feeding, certainly most fish ate very few prey in the time allotted. The top 2 feeders, however, contained hundreds of nematodes. Spot feeding on copepods contained, at most, a couple of hundred prey. In either case, fish contained amounts of prey that exceeded the lower detection limit of the antisera using RIE.

Prey proteins which become solubilized by digestive enzymes should, in the pilsed type of feeding trial used here, initially increase in concentration in the foregut and then gradually decrease as food is passed to the hindgut. In the hindgut, concentrations should increase as the meal is processed and then decrease through time. The negative slope of the regression line for nematode prey antigens in spot foreguts was consistent with the expected response. This was due to the decrease in antigen concentration with passage and degradation of the nematode food as it traveled from the foregut into the intestines or hindgut. The hindgut antigen concentrations increased over time as the food moved farther into the intestine. At some point in time, food in the hindgut would be digested beyond antibody 
recognition as antigenic determinants are destroyed. This would cause a reversal of the regression line slope from positive to negative as the nematode antigens were being broken down and absorbed by the intestine. This expected change in slope was not statistically significant in this study. However, in both fore- and hindguts, the decreasing number of detectable precipitin peaks from samples taken in the last 2 time periods (see Table 1) probably indicates the absorption or final breakdown of antigenic determinants by the digestive system.

If harpacticoid copepods had greater dietary value than nematodes, the apparent preference exhibited for epibenthic harpacticoids would at least be energetically, if not ecologically, meaningful to juvenile spot. Detailed analyses of the food value of meiofauna are not readily available. However, Couch (1989) found that the carbon-to-nitrogen ratio for both harpacticoid copepods and nematodes is equivalent at 3.9 . Cummins \& Wuycheck (1971) report the energy content of the harpacticoid copepod Tigriopus californicus as $5555 \mathrm{cal} \mathrm{g}^{-1}$ dry wt. Using this value, Volk et al. (1984) calculated that harpacticoid copepods were 35 to $40 \%$ better in supplying energy for growth of juvenile chum salmon than either a calanoid or an amphipod diet. Unfortunately, nematodes were not an alternate food source in their study.

A problem with interpreting measurements of the caloric content of copepods is that they include calories from the thick, chitinous exoskeleton which is expelled from the digestive tract as fecal waste (Sogard 1984). Therefore, caloric contents of ashed copepods includes the chitinous exoskeleton with carbon as a major component. The inclusion of the exoskeleton will bias carbon-to-nitrogen ratios in favor of the copepods, when in fact only the soft body tissues are of any caloric value to the fish.

In contrast, nematodes have a scleroprotein cuticle which is fully digestible (Hofsten et al. 1977). Since the entire body of the nematode is digested, their high lipid content (up to $41 \%$ of dry body weight), and in turn high caloric value (2.3 times that of carbohydrate per unit weight) would make the caloric content of nematodes $\left(6.1174 \mathrm{kcal} \mathrm{g}^{-1}\right.$ AFDW and $11.5423 \mathrm{kcal}$ $\mathrm{g}^{-1}$ of organic carbon) very appealing to predators (Sikora et al. 1977). It may be that copepods 'taste' or 'smell' better to fish than nematodes, but this is still conjecture (Chao \& Musick 1977). Because harpacticoid copepods such as Tigriopus spp. are naturally high in essential fatty acids (Watanabe et al. 1983), they may be eaten by juvenile fishes for their food quality as well.

We attempted to measure the feeding selectivity bias incurred by a more rapid digestion rate for nematodes than for copepods. Using data on gut contents of fish collected every $2 \mathrm{~h}$ and concurrent collections of meiofauna in the same area (Coull \& Feller 1988, Feller et al. 1990), calculations of selectivity using the odds ratio (Gabriel 1978) showed that copepods were always positively selected for, regardless of the abundance of nematodes visible in the guts. Nematode abundances in the field were evidently so much greater than those of other taxa that it would have been nearly impossible to detect negative selection for any other nonnematode taxon ingested. If the rate at which copepod prey enter the hindgut is higher than their rate of disappearance, then their exoskeletons could accumulate in the fish's hindgut prior to being defecated. Thus copepod abundances are even further exaggerated if hindgut contents are included in the calculations. The point to make, however, is that if selective digestion occurs in other fishes as well, the incidence of and, hence, importance of nematodes in fish diets has likely been severely underestimated. This point has been made previously by Gee (1989) regarding soft-versus hard-bodied prey but never directly tested until now. Reports that fish select harpacticoid copepods as prey and, by implication, avoid nematodes may be greatly exaggerated. We believed that juvenile spot eat nematodes incidentally as a type of by-catch when they bite sediment containing their 'preferred' prey, the surface-dwelling harpacticoid copepods

This study further illustrates the importance of a few key factors in determining fish dietary profiles, namely time of collection since fish last fed and digestibility of prey. Diet descriptions can be biased in many ways. We suggest that early post-feeding foregut samples are most representative and reliable for determining visually what juvenile spot and perhaps other fish species eat naturally.

Acknowledgements. We thank Andy Barnard, Bettye Dudley, Bob Ferguson, Brian Hentschel, Amy Nelson, Liesl Rhodes, and Greg Zagursky for their help in this study. Dr Don Edwards offered statistical advice. We thank Drs Bruce Coull. Mike Gee, and Melanie Austen for their editorial suggestions. Comments of anonymous reviewers were also most helpful. Part of the study was supported by a Research Experiences for Undergraduates award (for L.L.M.) as a supplement to NSF grant OCE 85-21345 from the Biological Oceanography Program (R. J. Feller and B. C. Coull, principal investigators). Writing support was provided to R.J.F. by NSF grant INT8912528 .

\section{LITERATURE CITED}

Archambault, J. A., Feller, R. J. (1991). Diel variations in gut fullness of juvenile spot, Leiostomus xanthurus (Pisces). Estuaries 14: 94-101

Billheimer, L. E., Coull, B. C. (1988). Bioturbation and recolonization of meiobenthos in juvenile spot (Pisces) feeding pits. Estuar coast. Shelf Sci. 27: 335-340 
Chao, L. N., Musick, J. A. (1977). Life history, feeding habits, and functional morphology of juvenile sciaenid fishes in the York River Estuary, Virginia. Fish. Bull. U.S. 75 $657-702$

Couch, C. A. (1988). A procedure for extracting large numbers of debris-free living nematodes from muddy marine sediments. Trans. Am. Microsc. Soc. 107: 96-100

Couch, C. A. (1989). Carbon and nitrogen stable isotopes of meiobenthos and their food resources. Estuar. coast. Shelf Sci. 28: $433-441$

Coull, B. C. (1985). Long-term variability of estuarine meiobenthos: an 11 year study. Mar. Ecol. Prog. Ser. 24: $205-218$

Coull, B. C. (1990). Are members of the meiofauna food for higher trophic levels? Trans. Am. Microsc. Soc. 109: $233-246$

Coull, B. C., Feller, R. J. (1988). Site-to-site variability in abundance of meiobenthic copepods along a tidal gradient over 24 hours. Hydrobiologia 167/168: 477-483

Cummins, K. W., Wuychek, J. C. (1971). Caloric equivalents for investigations in ecological energetics. Int. Ass. theor. appl. Limnol. Comm. 18: 1-158

Ellis, M. J., Coull, B. C. (1989). Predation on meiobenthos: field experiments using juvenile spot (Pisces). J. exp. mar Biol. Ecol. 130: 19-32

Feller, R. J., Coull, B. C., Hentschel, B. T. (1990). Meiobenthic copepods: tracers of where juvenile Leiostomus xanthurus feed? Can. J. Fish. Aquat. Sci. 47: 1913-1919

Feller, R. J., Taghon, G. L., Gallagher, E. D., Kenny, G. E., Jumars, P. A. (1979). Immunological methods for food web analysis in a soft-bottom benthic community. Mar. Biol. 54: $61-74$

Gabriel, W. L. (1978). Statistics of selectivity. In: Lipovsky, S. J., Simenstad, C. A. (eds.) Fish food habits studies. Proceedings of the Second Pacific Northwest Technical Workshop. Washington Sea Grant Publication, University of Washington, Seattle, p. 62-66

Gee, J. M. (1989). An ecological and economic review of meiofauna as food for fish. Zool. J. Linn. Soc. 96: 243-261

Grisley, M. S., Boyle, P. R. (1988). Recognition of food in Octopus digestive tract. J. exp. mar. Biol. Ecol. 118; 7--32

Hayward, R. S., Margraf, F. J., Knight, C. T., Glomski, D. J. (1989). Gear bias in field estimation of the amount of food consumed by fish. Can. J. Fish. Aquat. Sci. 46: 874-876

This article was submitted to the editor
Hentschel, B. T., Feller, R. J. (1990). Quantitative immunoassay of the proventricular contents of white shrimp (Penaeus setiferus Linnaeus): a laboratory study. J. exp. mar. Biol. Ecol. 139: 85-99

Hofsten, A. V., Kahan, D., Katznelson, R., Bar-El, T. (1983). Digestion of free-living nematodes fed to fish. J. Fish Biol 21: $419-428$

Hyslop, E. J. (1980). Stomach contents analysis: a review of methods and their application. J. Fish Biol. 17: 411-429

Kroll, J. (1983). Tandem Crossed Immunoelectrophoresis. Scand. J. Immunol. 17: 135-139

Laurell, C. B. (1966). Quantitative estimation of proteins by electrophoresis in antibody-containing agarose gel. Prot. Biol. Fluids 14: 499-502

Nelson, A. L., Coull, B. C. (1989). Selection of meiobenthic prey by juvenile spot (Pisces): an experimental study. Mar. Ecol. Prog. Ser. 53: 51-57

Pierce, G. J., Diack, J. S. W., Boyle, P. R. (1990). Application of serological methods to identification of fish prey in diets of seals and dolphins. J. exp. mar. Biol. Ecol. 137: 123-140

Roelofs, E. W. (1954). Food studies of young sciaenid fishes Micropogon and Leiostomus, from North Carolina. Copeia 2: $151-153$

Sikora, J. P., Sikora, W. B., Erkenbrecher, C. W., Coull, B. C. (1977). Significance of ATP, carbon and caloric content of meiobenthic nematodes in partitioning benthic biomass. Mar. Biol. 44: 7-14

Smith, L. D., Coull, B. C. (1987). Juvenile spot (Pisces) and grass shrimp predation on meiobenthos in muddy and sandy substrata. J. exp. mar. Biol. Ecol. 105: 123-136

Sogard, S. M. (1984). Utilization of meiofauna as a food source by a grassbed fish, the spotted dragoned Callionymus pauciradiatus. Mar. Ecol. Prog. Ser. 17: 183-191

Volk, E. C., Wissmar, R. C., Simenstad, C. A., Eggers, D. M. (1984). Relationship between otolith microstructure and the growth of juvenile chum salmon (Onchorynchus keta) under different prey rations. Can. J. Fish. Aquat. Sci. 41: 126-133

Watanabe, T., Kitajima, C., Fujita, S. (1983). Nutritional values of live organisms used in Japan for mass propagation of fish: a review. Aquaculture 34: 115-143

Yetman, K. T. (1979). The morphology of the buccopharyngeal filter of an estuarine fish, Leiostomus xanth urus. M.S. thesis, University of South Carolina, Columbia

Manuscript first received: June 27, 1990

Revised version accepted: March 1, 1991 